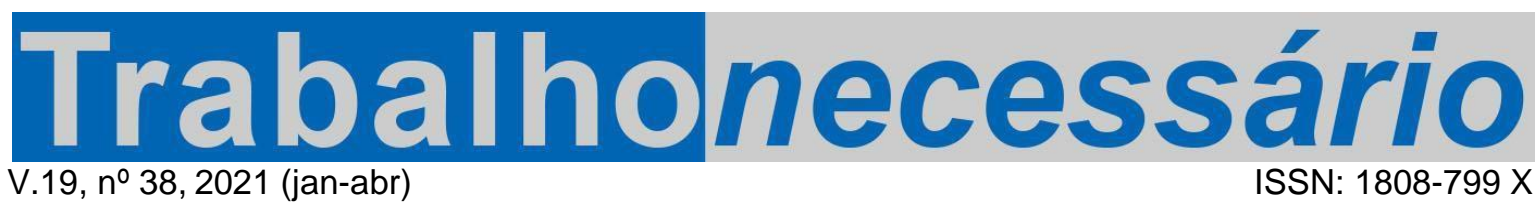

\title{
A NATURALIZAÇÃO DO FEMININO NO PROGRAMA DE AGENTES COMUNITÁRIOS DE SAÚDE NO BRASIL ${ }^{1}$
}

\begin{abstract}
Anna Violeta R. Durão²
\section{Resumo}

Esse artigo analisa as relações entre gênero e trabalho comunitário na Institucionalização da profissão das Agentes Comunitárias de Saúde (ACS) no Nordeste do Brasil. Na esteira de E.P. Thompson, recupera-se a história dessas trabalhadoras, considerando tanto as políticas mais amplas que direcionaram a sua formação, quanto a participação das agentes nesse processo. Constatou- se que a experiência de trabalho foi alicerçada em valores tradicionais da socialização feminina que se consolidaram na sobreposição de várias esferas da vida: na família, na religião e na comunidade.

Palavras-chave: Gênero; Agente Comunitária de Saúde; História e Trabalho Comunitário.
\end{abstract}

\section{LA NATURALIZACIÓN DE LO FEMENINO EN EL PROGRAMA DE AGENTES COMUNITARIOS DE SALUD EN EL NOROESTE DE BRASIL}

\section{Resumen}

El artículo analiza las relaciones entre género y trabajo comunitario en la institucionalización de la profesión de los Agentes Comunitarios de Salud (ACS) en el noroeste de Brasil. Fundamentado en E.P. Thompson, se recupera la historia de esas trabajadoras, considerando las políticas más amplias que direccionaron su formación, así como la participación de los agentes en ese proceso. Se constató que la experiencia de trabajo tuvo como base los valores tradicionales de la socialización femenina que se consolidaron en sobre posición de las diversas esferas de la vida: en la familia, la religión y la comunidad.

Palavras-chave: Género; Agente Comunitario de Salud; Historia y Trabajo Comunitario.

\section{THE NATURALIZATION OF WOMEN IN THE COMMUNITY HEALTH AGENTS PROGRAM IN NORTHEAST BRAZIL}

\begin{abstract}
:
This article analyzes the relations between gender and community work in the institutionalization of the profession of Community Health Agents (CHA) in the Northeast Brazil. In the wake of E. P. Thompson, the history of these workers was recovered, considering both the broader policies that directed their formation and the participation of agents in this process. It was found that the work experience was based on traditional values of female socialization that were consolidated in the overlapping of various spheres of life: in the family, in religion and the community.

Keywords: Gender; Community Health Agent; History and Community Work.
\end{abstract}

\footnotetext{
${ }^{1}$ Artigo recebido em 13/11/2020. Primeira avaliação em 02/12/2020. Segunda Avaliação em12/12/2020. Aprovado em 22/12/2020. Publicado em: 25/02/2021. DOI:https://doi.org/10.22409/tn.v19i38.47128 2 Doutora em Educação pela Universidade Federal Fluminense - UFF. Professora/pesquisadora da Escola Politécnica de Saúde Joaquim Venâncio/Fiocruz. E-mail annadura012@gmail.com. Lattes: http//lattes.cnpq.br//7221590839853064. ORCID: https://orcid.org/0000-0002-9795-557X
} 


\section{Introdução}

Esse trabalho analisa as relações entre gênero e trabalho comunitário na institucionalização da profissão das Agentes Comunitárias de Saúde (ACS) no Nordeste na década de 1990, quando foram contratadas mulheres como forma de diminuir a mortalidade materna infantil na região, sendo que um requisito para a contratação dessas trabalhadoras era/é que fossem moradoras das comunidades onde trabalham ${ }^{3}$.

As ACS estão presentes nas políticas de assistência, desde meados da década de 1970, atuando, principalmente, nas regiões Norte e Nordeste do país. No entanto, foi a partir dos anos 1990, com a criação do Programa de Agentes Comunitários em Saúde (PACS) que sua atuação passa a fazer parte de uma política mais ampla do Estado. Constatou-se que na sua formação ${ }^{4}$ perpassam as contradições entre uma política de caráter neoliberal de focalização na pobreza e a possibilidade de consolidação do Sistema Único de Saúde (SUS). De um lado, contrataram mulheres da mesma condição social do seu entorno como forma de minimizar a condição de pobreza gerada pelo aprofundamento da crise financeira e da diminuição do investimento do Estado nas políticas sociais. De outro, a incorporação das agentes, representava a possibilidade da construção efetiva do SUS, na medida em que a universalização do direito à saúde não poderia se dar sem a participação da população e as Agentes eram vistas como as principais mediadoras desse processo, responsáveis por estabelecer o elo entre os serviços de saúde e a comunidade (DURÃO, MOROSINI e CARVALHO, 2011).

Assim, a noção de comunidade está imbricada com o trabalho das agentes e foi entendida como extensão do trabalho doméstico, tendo estreita relação com uma visão essencialista do que é ser mulher. $O$ trabalho em tela analisa os sentidos dados a essa noção, colocando em relevo as contradições que o trabalho comunitário envolve quando perpassado pelas questões de gênero.

\footnotetext{
${ }^{3}$ Esse artigo traz alguns resultados da tese intitulada Relações de gênero na conformação de uma nova morfologia do trabalho: o fazer-se das agentes comunitárias de saúde (DURÃO, 2018).

${ }^{4}$ Vale destacar que se utiliza a palavra formação em sentido amplo, ou seja, como formação humana, no mesmo sentido que E.P. Thompson (2011) utiliza a palavra making, em seu famoso livro "The making of the English working class" que foi traduzido em português como "A formação da classe trabalhadora inglesa".
} 
No contexto atual de retrocesso, no qual somam-se a políticas econômicas neoliberais um conservadorismo moral, acredita-se que a recuperação histórica do processo de formação dessas trabalhadoras contribui para colocar em relevo a sua participação na construção do SUS e para o entendimento sobre as hierarquias de gênero que reforçaram/ reforçam o papel desigual das mulheres no mercado de trabalho, no cuidado e na família. Em termos mais amplos, lança luz sobre o trabalho do cuidado (care), que vem ganhando acento devido às mudanças no papel do Estado, que passa a restringir a sua atuação nas políticas sociais. A diminuição de creches públicas, o aumento da população idosa sem uma política pública que assegure os seus direitos, a entrada maciça das mulheres no mercado de trabalho, entre outras questões, colocam em pauta a profissionalização do trabalho do cuidado. Essas transformações apontam para a necessidade de se analisar a relação entre trabalho doméstico e trabalho remunerado, em outras palavras, o imbricamento entre a esfera privada e a pública (HIRATA; GUIMARÃES, 2012).

Para investigar o processo histórico da constituição dessas trabalhadoras além do levantamento da literatura mais ampla sobre trabalho e gênero, buscou-se fazer um estado da arte sobre o trabalho das Agentes e o direcionamento dado às políticas de Atenção Primária à Saúde no país ${ }^{5}$. Fundamenta-se no pensamento do historiador marxista de E. P. Thompson, principalmente nos conceitos de cultura, experiência e classe social.

O autor conceitua a cultura como todo um modo de luta. Ressalta, dessa forma, a relação de classe presente no capitalismo, como também a importância de se contrapor às formas hegemônicas de poder. Para Thompson, o embate entre classes está presente tanto nas lutas políticas mais amplas quanto no que cunhou de cultura costumeira, ou seja, naquelas lutas que se dão na disputa por diferentes saberes, valores, modos de vida que ocorrem no cotidiano. Decorre daí a importância da experiência, pois esta é entendida como "resposta mental e emocional seja de um indivíduo ou de um grupo social a muitos acontecimentos inter-relacionados ou a muitas repetições do mesmo tipo de acontecimento" (THOMPSON, 1981, p.194). A experiência constitui-se, portanto, como um conceito de junção entre a consciência e

\footnotetext{
${ }^{5}$ A Atenção Primária à Saúde, como sintetiza Matta e Morosini (2009, p. 44), refere-se a: "uma estratégia de organização da atenção à saúde voltada para responder de forma regionalizada, contínua e sistematizada à maior parte das necessidades da saúde de uma população, integrando ações preventivas e curativas, bem como a atenção a indivíduos e a comunidades".
} 
a realidade concreta que os homens e as mulheres, em um dado período histórico, vivenciam em suas múltiplas determinações, estando associado, a um só tempo, a uma experiência do sujeito e a uma experiência coletiva.

O esforço feito nesse artigo foi analisar como se deu o processo histórico ativo de constituição das Agentes, ressaltando a cultura costumeira que foram estabelecidas e se estabeleceram na repetição de algumas experiências que fizeram parte da sua formação.

Para tanto, utiliza como fonte primária o trabalho de Sousa (2011) que teve a iniciativa de entrevistar 50 mulheres pioneiras na implantação do PACS em diversos estados do país. A autora optou por deixar a fala das entrevistadas quase na íntegra, sem analisá-las. Dentre as entrevistas produzidas por Souza (2011), foram selecionadas aquelas ACS mais antigas, que tinham participado do início da implantação do PACS no Nordeste.

Primeiramente, contextualiza-se o direcionamento da política durante os anos de 1990, relacionando-a com a constituição das agentes. Em seguida, procura-se analisar as suas experiências de vida e de trabalho na passagem do trabalho doméstico para o trabalho comunitário remunerado.

\section{O feminino nas políticas sociais nos anos de 1990 e a implantação do PACS}

Vários autores (NEVES et al., 2005; ANZORENA, 2010), analisando o direcionamento das políticas sociais durante os anos de 1990, sinalizam a preocupação dos organismos internacionais com a coesão social na América Latina, pois, em face da retração do Estado nas políticas públicas, colocava-se em risco a paz na região. Desejava-se dar uma "face humana" aos ajustes macroestruturais impostos aos países pobres. O discurso de solidariedade e colaboração entre os membros de uma dada comunidade é enfatizado, sendo visto como capaz de reverter as desigualdades sociais e a pobreza.

Nesse sentido, a comunidade será entendida como lócus desse modelo de desenvolvimento diretamente relacionado às populações pobres, sendo a mulher considerada potencializadora de políticas públicas, devido aos papéis de cuidadora e educadora que realiza na família. Esse encaminhamento da política pretende diluir as contradições entre capital e trabalho, ressaltando uma suposta aliança entre as 
classes antagônicas em torno de objetivos comuns, tais como o combate à fome, à miséria etc. (FARAH, 2004; SIMÕES-BARBOSA, 2001).

Anzorena (2010) analisa que a valorização da participação feminina pelos organismos internacionais ocorreu sob o argumento de que as mulheres teriam uma superioridade moral dentro da comunidade. A autora esclarece que as agências internacionais e os governos se apropriaram de ideias como "cidadania ativa e participação por baixo", que foram fomentadas pelas Comunidades Eclesiais de Base, e as transformaram em ferramentas para a formulação de políticas que visavam a contrarrestar os problemas sociais e políticos. Essas políticas, ao mesmo tempo que buscam reduzir a responsabilidade do Estado nas políticas de assistência e seguridade social, valorizam as atividades femininas no campo da reprodução, em outras palavras, reforçam o papel histórico das mulheres no trabalho não remunerado do cuidado. Ao definir as mulheres-mães-pobres como as principais indutoras das políticas, naturalizam sua responsabilidade de cuidar do lar e do seu entorno, desconsiderando que elas são as mais prejudicadas pelas políticas de ajuste. Enfim, são políticas que, a um só tempo, buscam tirar proveito de habilidades vistas como femininas, como também das redes de solidariedade que as mulheres criam como estratégia de sobrevivência (ANZORENA, 2010). Farah (2004) destaca a recomendação do Banco Mundial que, com base na noção de feminilização da pobreza, fomenta a focalização em políticas para mulheres nas áreas de saúde, educação, geração de emprego e renda, entre outras, argumentando maior eficiência dessas políticas no combate à pobreza.

A institucionalização do trabalho das Agentes caminha nesse sentido, como é possível depreender do direcionamento dado pelo Estado para sua implantação. A implantação do Programa no estado do Ceará, serviu de exemplo para difusão do modelo para o resto do país. Em 1987, o estado vivia mais um período de seca e durante a estiagem, tradicionalmente, os chefes de família recebiam uma remuneração mensal como forma de alívio da pobreza que se acentuava nesses momentos. Em contrapartida, prestavam algum serviço ao município, na maioria das vezes, na manutenção das estradas (ÁVILA, 2011). Nesse ano, o estado privilegia a contratação de mulheres para diminuir a mortalidade materno-infantil. Nas palavras do então Secretário de Saúde do Ceará, Carlyle Lavor: 
Sempre na emergência se empregam os homens, mas há muitas mulheres que não têm marido, que são donas de casa. Então sugerimos empregar 6 mil mulheres, que era o cálculo que a gente tinha feito de agentes de saúde necessários para o estado. Foram selecionadas 6 mil mulheres dentre aquelas mais pobres do estado, que eram escolhidas por um comitê formado por trabalhadores, igreja, representantes do estado e município. (CARLYLE LAVOR apud NOGUEIRA; SILVA; RAMOS, 2000, p. 4).

O trabalho consistia no encaminhamento de gestantes para o pré-natal e para a maternidade, no incentivo ao aleitamento materno, na vacinação das crianças e em orientações de higiene. A melhora nos indicadores de saúde materno-infantil revelou a importância do trabalho dessas mulheres que deixou de ser uma ação pontual de caráter emergencial e passou a ser institucionalizado (ÁVILA, 2011). Indicativo, portanto, que o sentido dado à comunidade não tinha uma neutralidade nem de gênero, nem de classe. Foram contratadas mulheres proximamente identificadas com suas vizinhas. Amplia-se o cuidado, que sai do âmbito da casa para o espaço público, institucionalizando o trabalho do cuidar.

Nota-se no depoimento do então Secretário de Saúde, Carlyle Lavor, uma visão patriarcal sobre o trabalho feminino, na medida em que são destinatárias da política as mulheres que não têm marido, ou seja, que não estão sob a guarda, vale dizer, sob a dominação masculina. Constata-se, portanto, que mesmo com a complexidade das sociedades contemporâneas, as relações de poder patriarcal continuam presentes na dominação/exploração das mulheres.

Diante das transformações que ocorreram na reprodução do capitalismo, a inserção das Agentes é apresentada, pela política, como uma forma de geração de renda para mulheres que têm dificuldades de entrar no mercado de trabalho e que vêm sendo responsáveis pela manutenção da nova composição familiar, na qual, dentre outros arranjos, a mulher se configura como arrimo de família. Enquadra-se no que Fleury (2005) caracteriza como um modelo assistencial que abrange ações emergenciais dirigidas a grupos pobres mais vulneráveis em uma perspectiva caritativa reeducadora que, embora assegurem certos bens, não configuram uma relação de direito social, tratando-se de políticas compensatórias. O que a autora cunhou como cidadania invertida, na qual, para se ter acesso à proteção social, os grupos vulneráveis têm que provar sua não inserção no mercado de trabalho. No caso das ACS, o acesso a certos direitos refere-se a uma remuneração precária por um trabalho que elas já exerciam junto à comunidade. 
Em 1991, a experiência do Ceará se espraia para outros estados do Norte e Nordeste, constituindo o Programa Nacional de Agentes Comunitários de Saúde (PNACS). No ano seguinte, perde o termo nacional, passando a ser chamado de Programa de Agentes Comunitários (PACS), no qual, mais uma vez, contratam-se mulheres, priorizando-se o atendimento ao grupo materno-infantil (SCOTT, 2011).

Destacar-se-á a seguir algumas experiências que conformaram o trabalho/vida das Agentes. Essas experiências formaram elos intercessores, no qual o trabalho do cuidado na família se estendeu para o trabalho voluntário realizado junto às Pastorais da Criança e desse para o trabalho remunerado na comunidade.

\section{Relações de gênero e experiência no Programa de Agentes Comunitários em Saúde}

Em seu percurso de investigação, Sousa (2011) apresentava como primeira indagação às mulheres entrevistadas a questão: "Quem sou eu?". A maior parte das respostas enfatiza o papel de cuidadoras que elas desempenhavam na família. Assim, é esse o elemento que parece conferir sentido à sua vida e ao seu trabalho como ACS. Isso se explicita, por exemplo, na fala de uma Agente do Ceará: "estas são as coisas que eu sei fazer: ser mãe, Agente Comunitária de Saúde e dona de casa" (IRLANDIA/CE apud SOUSA, 2011, p. 45).

Evidencia-se a íntima relação entre a experiência de se fazer mulher e sua condição de classe, pois, no discurso das agentes, seu papel de mulher e de cuidadora na família e uma vida marcada pela adversidade são naturalizados como intrínsecos a seu ser. Sobreleva-se, portanto, na narrativa dessas trabalhadoras, uma dupla determinação. De um lado, uma determinação de classe, pois são mulheres que tiveram sua vida construída diante de condições mínimas para produzir a existência. De outro, uma determinação de gênero, na medida em que se estabelece uma relação linear entre o sexo e seu papel como cuidadora dos filhos, dos pais, do marido e da comunidade.

Vale esclarecer que se entende determinação no mesmo sentido que destaca Willians (2011), para quem o conceito, longe de ser entendido como uma causa externa que prediz e prefigura por completo uma atividade ulterior, atua como forma de fixar limites e exercer pressões nas práticas sociais. Nesse sentido, o autor 
compreende a hegemonia como práticas e expectativas que, ao serem vivenciadas, conferem sentido à vida e ao mundo. Nas palavras do autor:

Falo de um conjunto de significados e valores que, do modo como são experimentados enquanto práticas aparecem se confirmando mutuamente. A hegemonia constitui, então, um sentido de realidade para a maioria das pessoas em uma sociedade, um sentido absoluto por se tratar de uma realidade vivida além da qual se torna muito difícil mover-se e que abrange muitas áreas de suas vidas (WILLIANS, 2011, p. 44).

Como se buscou destacar, a política de institucionalização das Agentes teve um forte direcionamento de gênero que se relaciona com a experiência de vida dessas trabalhadoras. Vale analisar como essa hegemonia ganha sentido nas várias áreas que envolvem a sua vida e o seu trabalho e em que medida se contrapõe à cultura dominante, tendo em mente, como também aponta Willians (2011, p. 48-49), que a principal coisa que "um trabalhador produz é sempre ele mesmo, tanto nas condições específicas do seu trabalho, quanto na ênfase histórica mais ampla dos homens produzindo-se a si mesmos e a sua história".

Pode-se pensar, a partir de E. P. Thompson, em que medida é possível falar sobre uma experiência no feminino. Como já destacado, o conceito de experiência em Thompson está associado, a um só tempo, a uma experiência do sujeito e a uma experiência coletiva. Assim, na luta pela produção da existência, criam valores que ora se alinham, ora se distanciam da cultura dominante. Nesse sentido, o fazer-se mulher engloba várias experiências que formam um amálgama, no qual elas se constituem e são constituídas como mulheres trabalhadoras. Nessa relação, sua experiência de trabalho e vida é permeada por uma visão do feminino, culturalmente diferenciada da do masculino e marcada por sua condição de classe.

Para se pensar a experiência no feminino faz-se necessário entender as atividades domésticas como trabalho, na medida em que houve uma tendência de se enquadrar nessa classificação apenas o trabalho produtivo enquanto tal, separandose a esfera doméstica como lócus do feminino, e a esfera pública como lócus do masculino. Neste contexto, a reprodução social dos seres humanos ficou ao encargo das mulheres e, embora esse não seja diretamente produtivo ao capital, se tornou, nas relações capitalistas, elemento de mediação da reprodução da força de trabalho que engloba a nutrição, o cuidado, a educação, a socialização das crianças, entre 
outras atividades. Atividades estas que associadas ao amor materno, estabeleceram as bases ideológicas para a divisão sexual do trabalho.

O trabalho doméstico sempre foi central na vida das mulheres trabalhadoras, mesmo quando inseridas na produção. O peso desse trabalho esteve a seu encargo. Interessante perceber que, com o crescimento do desemprego e as políticas neoliberais correlatas, a política reforça essa centralidade, estendendo-a a outros espaços. Em outras palavras, em um momento de fragmentação, precarização do trabalho, aposta-se na centralidade do trabalho doméstico como forma de aliviar a pobreza. Se a partir da década de 1970, nos países centrais, passa-se a questionar a centralidade do trabalho, tendo como contexto a crise do fordismo, quando as políticas neoliberais se espraiam para os países periféricos, enfoca-se o trabalho das mulheres na esfera doméstica na tentativa de arrefecer a crise.

Vale a pena elucidar a contradição que o trabalho feminino traz. Por um lado, sua inserção no assalariamento corresponde a um trabalho unilateral, mutilador e alienado. De outro, a delimitação da sua participação na esfera doméstica limita a possibilidade de uma formação integral como ser humano ao seu corpo biológico, na qual a recuperação da força de trabalho será realizada por elas como trabalho não pago.

No entanto, o trabalho dessas mulheres no lar tem um forte valor de uso que é inerente à reprodução da existência, sendo regido, contraditoriamente, por uma ótica que não se afina, inteiramente, com a dimensão do mercado. A luta que elas travam para a sobrevivência é fortemente marcada pelo anseio de uma vida mais digna não só para si, mas para a população do seu entorno.

Ao se auto definirem, as Agentes destacam o seu papel de guerreiras, lutadoras que diante das dificuldades são capazes de dar um sentido positivo a seu trabalho e a sua vida, aliás aspecto também ressaltado em outras pesquisas (MENEZES, 2011; OLIVEIRA, 2015) que se debruçaram sobre as mulheres da classe trabalhadora. Acredita-se que a luta em que elas se inserem diz respeito, diretamente, à reprodução da existência, na medida em que, historicamente, se constituíram e foram constituídas para e no trabalho doméstico. Não por acaso, quando perguntadas sobre quem são, destacam o valor da família como inerente ao seu ser. Como destaca Lucia Gutemberg (ACS/BA apud SOUSA, 2011, p. 31), refletindo sobre a sua história de vida: 
Eu tinha vindo de uma história muito difícil, de uma infância muito difícil, porque os meus pais haviam se separado havia muitos anos, e era complexa a vida de uma mulher sozinha e separada, para criar cinco filhos. A minha mãe não teve a estrutura e abandonou a casa, e eu tive que sustentar toda a família e brigar com a vida dia após dia.

Nota-se, na constituição de vida dessas ACS, que o trabalho de cuidado com a família percorre a trajetória de vida das Agentes, tendo sido socializadas, desde a infância, para o papel de cuidadoras, que já realizavam quando crianças e que ganha relevância no seu trabalho atual junto a seus familiares se estendendo para o trabalho junto à comunidade. Souza-Lobo (2011, p. 89) chama essa percepção das mulheres como experiência de destino, onde "o trabalho, o casamento, a maternidade, sucedem-se naturalizados como os ciclos de vida". Nesse mesmo sentido, não há uma ruptura no papel de cuidadora. Mesmo as ACS mais velhas, que já tinham criado seus filhos, assumem esse trabalho ao cuidar dos netos e, muitas vezes, de outras pessoas não diretamente ligadas à sua família parental. Como destaca Antônia Regina de Souza Moura (ACS/CE apud SOUSA, 2011, p. 27):

Sou casada, tenho três filhos e moro no horto florestal há 27 anos. Tenho dois netos, dois filhos, que já são casados. Por enquanto, sou só eu e meu esposo em casa. Ainda crio um menino de 12 anos e tenho a minha mãe viúva com 84 anos, e a minha avó que tem 103.

Ao contrário da visão da mulher independente, emancipada, que "trabalha fora" e é dona do seu corpo, bandeira do movimento feminista na década de 1970, que não ecoava as experiências e vozes de outras mulheres, como as negras, as hispânicas, as indígenas, entre outras; o trabalho do cuidar ganha uma dimensão ontológica que se imbrica com a construção do corpo biológico, fundando-se no valor da família e da comunidade. Ontologia, aqui, compreendida não como uma visão metafísica do que constitui a natureza humana, mas construída historicamente no trabalho dessas mulheres na esfera doméstica. Pode-se dizer com Thompson (1998, p. 18) que as ACS se formaram e foram formadas dentro de uma cultura costumeira, na qual:

A criança faz o seu aprendizado das tarefas caseiras primeiro junto à mãe ou à avó, mais tarde (frequentemente) na condição de empregada doméstica ou agrícola. No que diz respeito ao mistério da criação dos filhos, a jovem mãe cumpre o seu aprendizado junto às matronas da comunidade. O mesmo acontece com os ofícios que não têm aprendizagem formal. Com a transmissão dessas técnicas particulares, dá-se igualmente a transmissão de experiências sociais ou da sabedoria comum da coletividade. 
Em que pese a enorme distância temporal que separa a análise de Thompson sobre a constituição da classe trabalhadora e o trabalho das ACS, pode-se inferir que o trabalho das Agentes nasce dessa aprendizagem não formal que se solidifica através de outras experiências que corroboram para fortificar uma dimensão essencialista do papel da mulher.

Dentre essas experiências, ganha relevo o trabalho voluntário realizado nas Pastorais da Criança, que se soma ao papel construído na família e transmite outros ensinamentos que serão repassados para as mulheres da vizinhança. Souza e Lautert (2008), ao se debruçarem sobre o conceito de trabalho voluntário, ressaltam que, na maioria dos estudos sobre o tema, esse é entendido como qualquer atividade onde as pessoas ofertam seu tempo livre para ajudar outros grupos/pessoas sem retribuição monetária. Difere-se ainda do trabalho remunerado, pois não possui um sistema de classificação e definição. Acrescentam que outra característica comum desse trabalho é o direcionamento às comunidades e às pessoas mais carentes do que o voluntário. Willians (2007) destaca que o serviço para a comunidade guarda um sentido antigo com o trabalho voluntário na medida em que é suplementar à provisão oficial ou ao serviço pago.

No início do século XX no Brasil, o trabalho voluntário se estabeleceu como um caminho encontrado pelas mulheres da elite para sair do confinamento do espaço doméstico. Por ser um trabalho sem remuneração, não representava um risco aos papéis estabelecidos para o feminino, vale dizer como esposa e mãe. A participação em trabalhos de caridade era vista como uma prova de altruísmo e de forte valor moral. Nesse sentido, fomentava-se o envolvimento das mulheres de classe alta para instruir e moralizar as crianças e as mulheres da classe trabalhadora (BESSE, 1999). Em grande medida, foi a partir do trabalho voluntário, agora realizado por mulheres da mesma classe social do seu entorno, que se deu o deslocamento do trabalho voluntário para a sua institucionalização.

Eu já fazia um trabalho voluntário pela pastoral da paróquia da comunidade de Brejo Santo, a paróquia do Sagrado Coração de Jesus. Sou líder da Pastoral da Criança, participo do coral da comunidade de Cabeceiras com o nome de Juventude Franciscana, e vi que, com o trabalho da Pastoral da Criança, eu juntaria o trabalho em uma comunidade só e faria um complemento (MARIA DE LOURDES SILVA/CE apud SOUSA, 2011, p. 49-50). 
O trabalho da Pastoral da Criança se originou nos marcos dos movimentos progressistas da Igreja Católica na década de 1980. No entanto seu discurso ganhou um novo direcionamento: a opção pelos pobres e a libertação afastaram-se da relação com mudanças econômicas e passaram a enfatizar o engajamento em ações concretas, optando pelo trabalho no cotidiano e por práticas relativas ao domínio privado. As ações emergenciais para salvar vidas ganham relevo, secundarizando as desigualdades da sociedade brasileira. Neste contexto, "não basta mulheres e homens dizerem que a situação está ruim e gritarem pelos seus direitos. Isto é bom e necessário, mas elas e eles querem também ações concretas agora, pois mortes que poderiam ser evitadas estão ocorrendo" (PASTORAL DA CRIANÇA apud ANJOS, 2007, p. 30). A ação da pastoral passa a ter como foco da atenção os cuidados com crianças de zero a seis anos e, como destaca Anjos (2007), apesar do trabalho não se restringir ao atendimento de mulheres grávidas e de crianças, mais de $90 \%$ eram mulheres.

Como sinaliza Saffioti (2013), a ação inovadora da Igreja, que poderia resultar do princípio cristão da igualdade entre os homens, esbarra, não só, no perigo da eliminação da consciência religiosa, como também pode abalar sua posição na estrutura de poder. Nesse sentido, a autora sinaliza que "as medidas progressistas que a Igreja tem apoiado dentro dos programas da democracia cristã visam à preservação do sistema capitalista de produção e à conservação da estrutura de poder que essa sociedade permite" (SAFFIOTI, 2013, p. 141). Não por acaso, durante o pontificado de João Paulo II (1978-2005), personagens ligadas à Teologia da Libertação foram questionadas, pois, para Roma, o risco de ideologizar a fé deturpava perigosamente os objetivos da Igreja (COSTA, 2015). No que tange à questão feminina, Saffioti (2013) destaca que a Igreja Católica, através de técnicas sociais que visam moldar o comportamento humano, reforça a posição subordinada da mulher, adequando-a ao status quo.

Embora sob outra perspectiva teórica, Anjos (2007, p. 28) corrobora com o pensamento de Saffioti, analisando que a mobilização para o trabalho, nas Pastorais da Criança, se deu a partir da construção de identidades e papéis femininos, reforçando a relação entre o corpo e a função como mãe. Reproduz-se, dessa forma, a atuação da mulher no espaço privado. Nas palavras da autora, recorre-se "a mecanismos de educação dos corpos e de 'somatização' do arbitrário cultural'. Nesse 
sentido, reforça-se uma identificação do papel da mulher como mãe, bem como se naturaliza o amor materno.

Costa (2015), analisando o discurso de Zilda Arns, famosa intelectual orgânica da Igreja, sinaliza que o trabalho comunitário é exaltado, compreendendo o esforço comunal em torno de um objetivo repartido e visto como missão que visa, nesse contexto, à transformação da dura realidade. Assim, o trabalho voluntário realizado nas pastorais, não é visto como uma escolha, mas um chamamento - vocação - no qual seu exercício é entendido como um serviço, ou uma missão. Tal compreensão vai de encontro à construção da profissão que pressupõe um ganho material (SEIDL, 2012).

Não por acaso as Agentes definem seu trabalho como ACS como missão, deslocando os objetivos do trabalho voluntário nas Pastorais para o trabalho no SUS. "Elenita, como pessoa, como ser humano, também é uma serva de Deus, que não vive só para pregar o Evangelho da Paz, mas também para a missão de fazer com que a saúde pública aconteça em nosso país" (ELENITA RAOLIM/CE apud SOUSA, 2011, p. 28), ou como reforça outra entrevistada: "Maria dos Anjos é uma daquelas pessoas que não desistem. Eu gosto de lutar. Ser Agente de Saúde para mim, não é só uma profissão, eu encaro como uma missão" (MARIA DOS ANJOS/PE apud SOUSA, 2011, p. 33).

A missão no momento da implantação do PACS era, principalmente, acabar com a diarreia e com a desnutrição que atingiam as crianças do Nordeste do país. Com efeito, conforme o Ministério da Saúde, em 1991, a taxa de mortalidade infantil era 71.2 por mil nascidos vivos, no Nordeste (BRASIL, s/d). Vale lembrar que a Pastoral se notabilizou pela utilização do "soro caseiro" no combate à desnutrição, bem como pela "farinha multimistura" ministrada como complemento nutricional. O primeiro era indicado para uso emergencial, já a segunda para uso contínuo (COSTA, 2015). Em que se pese a importância dessas ações para minimizar a mortalidade infantil, quando não se questionam as determinações do processo saúde-doença, nas quais as crianças e os adultos estão inseridos, acaba-se por normalizar o estado de pobreza. No caso da "missão" das ACS, coloca-se nos ombros das Agentes a responsabilidade pela superação da pobreza, na qual elas mesmas estavam submersas. Esquecendo-se que "a individualidade que possuímos e a natureza que desenvolvemos (nutridos, subnutridos, abrigados, sem-teto, sem-terra, etc.) estão subordinados ou resultam de determinações sociais que os homens (e as mulheres) 
assumem historicamente" (FRIGOTTO, 2002, p. 13). Nesse sentido, a formação das Agentes para o cuidado apreendida no espaço da família, como também no trabalho voluntário junto às Pastorais da Criança, reforça, mutuamente, a "natureza" de gênero e de classe em que estão inseridas.

Na passagem do trabalho voluntário para o remunerado, o pagamento não é, a princípio, visto como um direito, pois o mesmo trabalho já era realizado nas horas vagas. Ser remunerada é percebido como uma ajuda a mais para facilitar algo que 'naturalmente' já realizavam. Se o que marcava a inserção de mulheres no trabalho voluntário é a ideia de realizar uma missão, uma doação em nome de uma causa superior, a remuneração aparece como algo bom, mas não muito ressaltado nos depoimentos, na medida em que contradiz a própria ótica do voluntariado.

O perfil do agente era ser líder comunitário, era participar do trabalho da comunidade, e essa era minha cara. Quando eu me inscrevi, vi que era tudo aquilo que eu gostava de fazer, que era o meu trabalho, que eu ia ter um complemento, e que eu ia apenas passar a ser remunerada por aquilo que eu já fazia (LUIZA ROSA DA SILVA/PE apud SOUSA, 2011, p. 47).

$\mathrm{Na}$ contradição que o próprio trabalho feminino engendra, Lourdes Moraes fala da importância da remuneração, mesmo sem direitos, para sua vida, pois trabalhar como ACS possibilitou abandonar o trabalho na casa dos outros e, ao mesmo tempo, perceber que ela tinha direito a ter direito, nas palavras da entrevistada, e que podia lutar para a melhoria do trabalho.

(...) quando comecei o trabalho pela pastoral como Agente Comunitária de Saúde, eu não era paga. Depois apareceu a Unicef, que nos dava uma bolsa. Para falar a verdade, essa bolsa que ganhávamos em dinheiro caiu do céu. Deixei de ser empregada doméstica e de trabalhar na casa dos outros e comecei a ser Agente Comunitária de Saúde, ganhando essa bolsa. Foi aí que veio a ideia de lutarmos juntos para a melhoria desse trabalho (LOURDES MORAES/PE apud SOUSA, 2011, p. 46).

Vale esclarecer que, no momento da implantação do PACS, as Agentes eram pagas através de bolsas concedidas pela Unicef nos marcos da atenção primária seletiva, ou seja, privilegiando ações de orientações preventivas de técnicas simples para a diminuição da mortalidade infantil. O que compunha o pacote GOBI sigla em inglês que, como esclarecem Fonseca, Morosini e Mendonça (2013, p. 538): "combina os procedimentos growth monitoring (acompanhamento do crescimento), oral 
rehidration (reidratação oral), breast feeding (aleitamento materno) e immunization (imunização)".

Se a concessão do tempo para o trabalho voluntário era da prerrogativa da própria agente, com o PACS o trabalho passa a ser mais sistematizado, ampliando tanto as famílias atendidas, quanto o grau de informação e de orientação que eram repassadas. No começo do Programa o foco do trabalho das Agentes era a mortalidade materno-infantil, com o passar dos anos, ampliam-se as atribuições das ACS e elas passam a ser responsáveis pela prevenção de outras doenças que atingem a maioria da população, tais como: tuberculose, hanseníase, diabetes, entre outras. O espaço de atuação se estende para a casa das famílias, havendo um limite tênue entre a vida privada e o trabalho remunerado. Ao contrário da fábrica, na qual a inserção das mulheres se dá em espaços/tempos e relações diferenciadas, no trabalho como Agente o tempo e o espaço se imbricam, estreitando ainda mais as ralações que as trabalhadoras já tinham com a comunidade.

Assim, o papel feminino de cuidadora na família, reforçado pela Igreja, ganha pleno sentido no trabalho junto à comunidade, pois as crianças atendidas pelas agentes são crianças que fazem parte da vizinhança, são integrantes de famílias que elas conhecem e acompanham seu crescimento. Além disso, as lutas pela sobrevivência enfrentadas por essas famílias não se diferem das enfrentadas pelas Agentes. Há, portanto, uma identidade entre as mulheres usuárias do Programa e a própria vida. "É muito bom quando nos identificamos. Quando você vai a sua comunidade, encontra um problema que tem alguma coisa para resolver e você consegue" (LUIZA ROSA DA SILVA/PE apud SOUSA, 2011, p. 61).

Nas ações concretas no cotidiano, no enfrentamento das adversidades, percebem o valor do seu trabalho e são reconhecidas pela comunidade, sendo o trabalho permeado por uma visão coletiva de preocupação com o outro. No entanto, essa mesma identificação causa sofrimento ao perceberem os limites tanto de sua atuação, como de sua própria vida: "Agora está melhor. Era tão doloroso. ĺamos orientar as mães, mas quando íamos ter notícias, elas diziam que faltava alimentação, e eu via que na minha casa faltava a mesma coisa" (LOURDES MORAIES/PE apud SOUSA, 2011, p. 61). Assinala-se que quando só se ressalta as ações concretas no cotidiano como forma de amenizar a pobreza, acaba-se por gerar uma lógica perversa, na qual os próprios sujeitos são responsabilizados e se veem responsáveis por mudanças que estão muito além das suas possibilidades. É na luta diária junto à 
comunidade que criam laços de pertencimento e estratégias de sobrevivência que se retroalimentam.

Por ser da comunidade, vejo a luta diária e nos auto ajudamos mesmo. Para mim é muito mais que fazer a prevenção. Uma vez, uma instrutora nossa perguntou assim: 'Como você chega nas suas famílias? ' Eu não chego lá e pergunto a Dona Maria como ela está hoje. De jeito nenhum. Eu logo vejo se ela está feliz. Afinal, são 23 anos de Agente Comunitária de Saúde e temos uma história ali. Na minha comunidade, é assim, quando cheguei lá, só havia três casas. A partir daí a comunidade foi crescendo. Ajudamos a construir a comunidade. Durante a construção não tinha escola, não tinha posto de saúde, faltava tudo. Eu era uma Agente Comunitária de Saúde (LUCIA GUTEMBERG/BA apud SOUSA, 2011, p. 46).

Nota-se no depoimento de Lúcia Gutemberg o forte vínculo com as pessoas atendidas que vai muito além de procedimentos prescritos de como se abordar as famílias, nas suas palavras, "de fazer a prevenção". São conhecimentos tácitos adquiridos na constituição tanto da sua história de vida, quanto da própria comunidade. Trabalho que ganha sentido devido ao seu caráter necessário e inevitável e que não se dá somente por imposição externa, mas pelo envolvimento na luta por uma vida mais digna junto à comunidade.

Dessa maneira, as ACS estabelecem relações afetivas e solidárias que permitem contrarrestar, em parte, a dura realidade. Um trabalho construído a longo prazo, que se dá através de relações duráveis, alicerçado nos vínculos com a comunidade. Acrescenta-se que, como há um imbricamento entre o trabalho e a moradia, não existe um distanciamento entre as questões que envolvem o dia a dia de trabalho das Agentes e outras questões referentes à população, pois todas estão inseridas no mesmo contexto.

Lucia Gutemberg também ressalta a importância do trabalho no PACS como elemento que possibilitou aumentar sua autoestima e romper com o cerceamento de trabalhar na esfera doméstica. A perspectiva de ser remunerada, de fazer uma prova para admissão se constituíam como uma possibilidade de caminho para romper com as amarras da vida doméstica, como também com as relações de poder dentro de casa. Como se constata em seu depoimento sobre o processo de seleção para ser ACS e sobre a reação do seu marido: "Não estuda não porque lá só tem gente boa e isso não vai dar em nada. Eu pensei: 'Se eu fizer eu passo'. Eu chorei a noite toda achando que não conseguiria. Estava sem estudar há 12 anos" (LUCIA GUTEMBERG/BA apud SOUSA, 2011, p. 31). 
Os requisitos básicos para a contratação das ACS à época eram saber ler e escrever e ser moradora da comunidade. Constata-se, portanto, em pleno século XX, o grande hiato presente na educação brasileira quanto à premissa liberal sobre a necessidade de uma educação universal, pública e gratuita. Nesse contexto, observase a dualidade da aprendizagem presente nos primórdios da implantação da escola, onde se separou/separa de um lado a educação formal e de outro a educação comunitária, onde se dá o saber fazer sobre a existência e sobre as formas culturais do local, sendo no "trabalho concreto que se educa para ele" (RODRIGUES, 2016, p. 360).

No entanto, o trabalho feminino ao deslocar-se para a esfera pública, trouxe consigo uma demanda pelo aumento de escolarização, tanto por parte das trabalhadoras, como por parte do Estado, pois como foi salientado, o trabalho das ACS ao se institucionalizar vai incorporando novas funções que requerem um maior nível educacional.

Enfim, buscou-se, na esteira de Thompson, analisar as transformações no trabalho das Agentes em sentido amplo, ou seja, na sua relação com o trabalho doméstico, com a religião e com a comunidade, tentando desvelar o intrincado processo que envolve a formação, principalmente, quando inscrita no feminino.

\section{Considerações finais:}

Pode-se dizer com Thompson que no momento de implantação do Programa de Agentes Comunitários no Nordeste a passagem do trabalho doméstico ao trabalho remunerado se deu através de uma experiência herdada, na medida em que as normas, os valores e as atitudes que conformaram o seu ser social estavam de tal forma articulados com o seu corpo biológico que eram percebidos como determinados, no sentido estreito do termo. Com a implantação do PACS a centralidade do seu trabalho no lar amplia-se para a população do entorno, ganhando sentido em suas vidas, como também dentro da comunidade. Ao passarem a ser remuneradas, mesmo que com bolsas e contratos verbais, essa inserção lhes possibilitou outro status, dentro daquele contexto. Nesse percurso colaboraram para a diminuição da mortalidade infantil, para a vacinação das crianças, para o acompanhamento do pré-natal, facilitaram o acesso aos serviços de saúde, entre muitas outras contribuições. 
Passados mais de 30 anos da consolidação das ACS como uma política de Estado, as Agentes foram consolidando uma cultura do trabalho alicerçada nos valores da socialização feminina. Tentou-se manter um lugar bem delimitado e cerceado para essas mulheres, reforçando a diferença de classe e gênero da sua constituição. No entanto, como alerta Thompson (1998, p.16), falar de cultura é destacar uma arena de elementos conflitivos, ou seja, de "fraturas e oposições existentes dentro do conjunto".

Com efeito, embora a profissão das ACS ainda seja permeada por uma cristalização do que se entende como trabalho feminino que corrobora para a precarização do seu trabalho, as Agentes, no processo de constituição do seu trabalho, organizaram-se politicamente e lograram algumas conquistas, tais como: o reconhecimento da profissão, a qualificação técnica, o estabelecimento de um piso salarial nacional, entre outras.

No entanto, considerando a intensificação das políticas neoliberais nos últimos anos, esses avanços continuam ameaçados com forte possibilidade de retrocesso. Tem-se a esperança de que o esforço de rememoração do processo da sua formação, feito nesse artigo, contribua para que a luta dessas mulheres não se apague e atualize-se.

\section{Referências}

ANJOS, G. dos. Maternidade, cuidados do corpo e "civilização" na Pastoral da Criança. Revista de Estudos Feministas. Florianópolis, v.15, n.01, jan/abr, 2007, p. 27- 44. Disponível em: <http://dx.doi.org/10.1590/S0104-026X200700010000>. Acesso em: 10 mai. 2016.

ANZORENA, C.. 'Mulheres': destinatárias privilegiadas de los planes sociales de inicios del siglo XXI - Reflexiones desde uma perspectiva crítica de género. Revista de Estudos feministas. Florianópolis, n.18, set/dez, 2010, p. 725-746.

ÁVILA, M.M.M. Origem e evolução do programa dos agentes comunitários de saúde.

RBPS. Fortaleza, v.24, n.02, abr/jun, 2011, p. 159-168. Disponível em: <http://www.bioline.org.br/pdf?bh11024>. Acesso em: 10 jan. 2016.

BESSE, S.K. Modernizando a desigualdade de gênero. Reestruturação e ideologia de gênero no Brasil: 1914-1940. São Paulo: Edusp, 1999.

BRASIL, Ministério da Saúde. Taxa de mortalidade infantil. s/d. Disponível em: $<$ http://tabnet.datasus.gov.br/tabdata/livroidb/2ed/CapituloC.pdf>. Acesso em: 31 jun. 2016. 
COSTA, S. G. Proteção social, maternidade transferida e lutas pela reprodução social. Estudos Feministas. Rio de Janeiro, ano 10, 2002, p. 301-323. Disponível em: http://www.scielo.br/pdf/ref/v10n2/14959. Acesso em: 30 dez. 2016.

DURÃO, A. V. R. Relações de gênero na conformação de uma nova morfologia do trabalho: o fazer-se das agentes comunitárias de saúde. 2018, 236f. Tese (Doutorado em Educação) - Universidade Federal Fluminense, Niterói.

MOROSINI, M. V; CARVALHO, V. O ACS e o conceito de comunidade na configuração de sua qualificação. In: VIEIRA, M.; DURÃO, A. V.; LOPES, M. (Orgs.). Para Além da Comunidade: o trabalho e a qualificação do Agente Comunitário de Saúde. Rio de Janeiro: EPSJV, 2011, p. 119-159

FARAH, M. Gênero e políticas públicas. Estudos Feministas. Florianópolis, v. 12, n. 1, jan/abr. 2004, p. 47-71. Disponível em: <www.scielo.br/pdf/ref/v12n1/21692>. Acesso em: 23 ago. 2013.

FLEURY S. A seguridade social e os dilemas da inclusão social. RAP. Rio de Janeiro v.39, n.03, mai/jun, 2005.2 Disponível em:<Https://www.researchgate.net/publication/253310057>. Acesso em: 3 fev. 2016.

FONSECA, A; MOROSINI, M.V. G. C.; MENDONÇA, M. H. M. Atenção Primária à Saúde e o perfil social do trabalhador comunitário em perspectiva histórica. Trabalho, Educação e Saúde. Rio de Janeiro, v.11 n.03, set/dez, 2013, p. 525- 552.

FRIGOTTO, G. Juventude, trabalho e educação. In: TIRIBA, L. e CIAVATTA, M. (Orgs.). Trabalho e educação de jovens e adultos. Brasília: Liber Livro e Editora UFF, 2011, p. 99-133.

HIRATA, H; G, NÁDIA A. Introdução. In: Helena Hirata e Nádia Araújo Guimarães (orgs.). Cuidado e cuidadoras: as várias faces do trabalho do care, São Paulo, Atlas, 2012.

MATTA, G.; MOROSINI, M. Atenção primária à saúde. In: PEREIRA; LIMA, J (Orgs.). Dicionário da educação profissional em saúde. Rio de Janeiro: EPSJV, 2009, p. 4450.

MENEZES, C. Trabalhadeira, mulher e guerreira: o (precário) trabalho das agentes comunitárias de saúde. 2011. 127f. Dissertação (Mestrado em Saúde Coletiva.)

- Universidade Federal do Rio de Janeiro, Rio de Janeiro.

NEVES, L. M, et al. A Nova Pedagogia da Hegemonia: Estratégias do Capital para Educar o Consenso. São Paulo: Xamã, 2005.

NOGUEIRA, R; SILVA, F; RAMOS, Z. A vinculação institucional de um trabalhador sui generis: o agente comunitário de saúde. Rio de Janeiro: Ipea, 2000. Disponível em: $<$ www.ipea.gov.br/agencia/images/stories/PDFs/TDs/td_0735.pdf>. Acesso em: 5 set. 2015. 
OLIVEIRA, L. B. Experiência de Classe e Experiência de Gênero: trabalho, educação e (re) produção da vida social. 2015. Dissertação (Mestrado em Educação) Universidade Federal Fluminense, Niterói.

RODRIGUES, J. Por um programa de transição para a educação em defesa da concepção marxista de formação politécnica. In: VENÂNCIO, Escola Politécnica de Saúde Joaquim Venâncio (Org). Caminhos da politecnia: 30 anos da Escola Politécnica de Saúde Joaquim Venâncio. Rio de Janeiro: EPSJV, 2016, p. 357-401.

SAFFIOTI, H. A mulher na sociedade de classe: mito e realidade. São Paulo: Expressão Popular, 2013.

SCOTT, P. As famílias que os programas de saúde pública constroem no Brasil. In: NASCIMENTO, P.; RIOS, L. F. (Orgs.). Gênero, saúde e práticas profissionais. Recife: Universitária, 2011, p. 13-50.

SEIDL, E. Sociologia da Vocação Religiosa: reprodução familiar e reprodução da Igreja. Sociologias. Porto Alegre, ano 14, n. 29, jan/abr, 2012, p. 240-272. Disponível em: $<$ http://seer.ufrgs.br/index.php/sociologias/article/view/26373/15385>. Acesso em: 31 ago. 2015.

SIMÕES BARBOSA, R. H. et al. Gênero e trabalho em Saúde: um olhar crítico sobre o trabalho de agentes comunitárias/os de Saúde. Interface. Botucatu, v. 16, n. 42, p. 751765, Set. 2012. Disponível em: http://www.scielo.br/scielo.php?script=sci_arttext\&pid=S1414$32832012000300013 \&$ Ing=en\&nrm=iso >. Acesso em: 23 Mar. 2018.

SOUSA, M.de F.Mulheres na Saúde: Vozes coletivas, imagens singulares - 20 anos de PACS no Brasil. Campinas: Saberes editora, 2011.

SOUZA-LOBO, E. A classe operária tem dois sexos: trabalho, dominação e resistência. São Paulo: Fundação Perseu Abramo, 2011.

SOUZA, L M de; LAUTERT, L. Trabalho voluntário: uma alternativa para a promoção da saúde de idosos. Revista Escola de Enfermagem. São Paulo, v.42, n.02, 2008, p. 363-370. Disponível em:

$<$ http://www.scielo.br/scielo.php?script=sci_arttext\&pid=S0080-

$62342008000200022 \&$ Ing=en\&nrm=iso >. Acesso em: 30 jan. 2016.

THOMPSON, E. P. Costumes em comum. São Paulo: Companhia das letras, 1998.

A formação da classe operária inglesa: A árvore da liberdade. V.1. Rio de Janeiro: Paz e Terra, 2011.

A miséria da teoria ou um planetário de erros. Rio de Janeiro: Zahar, 1981.

WILLIANS, R. Cultura e materialismo. São Paulo: Unesp, 2011.

Paulo, Boitempo, 2007.

Palavras-chave: um vocabulário de cultura e sociedade. São 